\title{
Didactical Thinking and Suggestions on Oil and Gas Storage and Transportation Engineering Specialty
}

\author{
Bin Huang ${ }^{a}$, Cheng Fu \\ College of Petroleum Engineering, Northeast Petroleum University, Daqing, China \\ aemail38688359@qq.com, bemail:64944831@qq.com \\ ${ }^{*}$ Cheng $\mathrm{Fu}$ is the corresponding author of this paper.
}

Keywords: oil and gas storage and transportation professional; teaching situation; teaching suggestions

\begin{abstract}
China's petroleum colleges and universities, the quality of teaching directly determines the student's ability to adapt to the job after they are employed. In this text, we aim at the problems in oil and gas storage and transportation teaching, discussed the status of the teaching profession of oil and gas storage and transportation and make a summary of relevant teaching and give several related teaching suggestions.

In recent years, China's oil and gas pipeline network construction scale is gradually increasing, and oil and gas product warehousing industry is also in the large-scale development, and the domestic oil and gas industry is gradually moving towards the world.In this context, it is very urgent to cultivate high-quality talents of oil and gas storage and transportationprofessional. Oil and gas storage and transportation professional is the carrier of training talents in Petroleum College Culture, so the teaching quality of specialized courses plays a key role in the development ofoil and gas storage and transportation professional.

Oil and gas storage and transportation engineering is in the middle reaches of the oil industry, including oil and gas mineral collection processing, long distance transportation, storage and network transmission and distribution, which is the link of oil and gas production, refining, marketing, various links connected. It not only connects with the oil exploration and development of the professional engineering,chemical engineering, transportation engineering, but also the construction of a transnational natural gas pipeline and conveying media pluralism. This specialty has gradually become a comprehensive engineering ${ }^{[1]}$. This paper combines theprofessional teaching, professional practice teaching and classroom and practice and presents the methodswhich contribute to the improvement of oil and gas storage and transportationteaching. It also proves that we canonly improve the teaching quality of oil and gas storage and transportation by combining the methods for facilitating the teaching quality improvement.
\end{abstract}

\section{Professional course present teaching situation and related suggestions}

In the teaching of engineering courses in the past, teaching content tends to be simply interpreted as a textbook, and it is easy to form the "echo what the books say" teaching method, resulting in the limitations of teaching content and teaching method, leading to dull teaching atmosphere. A survey shows that graduates think that one of the places most neededto be improved in the professional teaching is the course content not practical or old ${ }^{[2,3]}$.Comparing with the basic theoretical courses ,professional coursespay more attention to the practicality and development of academic.The early period of oil and gas storage and transportation teaching tasks aim atletting students understanding the transportation system and the long-distance crude oil gathering pipeline system, but with the oil and gas storage and transportation industry developing rapidly in China, the oil and gas storage and transportation professional is constantly expanding. The problems are also in constant development and change. So the classroom teaching content of the specialty should also make certain changes according to the professional engineering problems. When planningthe professional teaching content, we should pay attention to combining with the actual problems and 
focus on the thoughts and methods solving the professional engineering problems, training students' basic ability of solving engineering problems.

The author learned that in the institutions which open oil and gas storage and transportation professional, oil and gas storage and transportation professional course is usually tested through the exams, which leads to many students just review the related classroom content and ignore the other knowledge content. That will make the students not familiar with or understand much knowledge in thepost-employment. And they even know nothing about many professional contents.

According to the status of teaching professional courses, the following suggestionsare given:

1.The professional course of oil and gas storage and transportation engineering also has thecharacteristicsof distinct academic frontier and inquiry, and this particularity determines that when the teachers teaching basic knowledge of this course, they must add the latest developments and achievements in scientific research and other contents to the teaching. This will expand the horizons of the students and let them understand the subject frontier and track the development trend of the discipline. But because the content of a certain professional frontier exploration have some uncertainties, so the teachers, when updating the course content,have the responsibility tochoose reasonable contents. At the same time, in order to achieve good teaching effect, cutting-edge content should be based on the domestic status and appropriate advanced, not to be too advanced ${ }^{[4]}$.

2. Classroom teaching should be flexible in the use of various teaching methods, and cultivate students' interests in learning. Classroom teaching is a main method of specialized course teaching. The lecture is a special art. In order to attract the students in the classroom teaching, teachers need to carefully prepare lessons before class. Teachers' preparationfor lessons should not only to prepare the teaching content, but also to understand students, teaching methods. On the dialectical relationship between teaching and learning, teachers should pay more attention to the students' main status, and mobilize students' enthusiasm, initiative and creativity.Student's enthusiasm, initiative and creativity can be mobilizedby teachers'combination of various teaching methods.

3. The way of examination shouldbe diversified, and expand students' width ofknowledge.

The way of professional courses examination should not only be limited in the form of test. The test is greatly limited students'knowledge, so teachers should explore one or more comprehensive examination methods. For example, in the usual teaching process, they can as much as possible inspire the autonomy learning of the students and allow students to be responsible for part of classroom teachingindependently. This will makethe classroom teaching mode diversified, and not only improve the students' learning efficiency, but also exercise the students' speaking abilities. Through the preparation for a lesson, students can learn much knowledge, and it also expanded their width of knowledge, which lays a good foundation for their future professional employments.

\section{II.Professional practice teaching status and related suggestions:}

Professional practice teaching is an important practice link in oil and gas storage and transportation professional. The traditional practice of teaching is in accordance with the training objectives of higher education. It is organized and planned to guide the college students to learn engineering and society in-depth, and then to improve the comprehensive quality and practice ability of the students. Takethe oil and gas storage and transportation as an example, the practice teaching contents mainly includes: basic course experiments, specialized experiments, professional curriculum design, production practice, comprehensive training, and graduation design. Our general training modes of university students emphasize the combination of theory and practice. Because of theobjective conditions or subjective factors, practice teaching program cannot be effectively implemented, which leads to students' poor ability and lacking of innovation ${ }^{[1]}$.

At the present stage of the production practice, the students usually only learn a particular aspect of the production processes and cannot have a complete understanding of the main production process of storage and transportation engineering. As teachers' and internships' concerns about security issues, it is difficult for students who are in the internships to do hands-onpractices, which 
results in students not mastering the contents. In addition, the practice unit' processat present isbackward, andcannotkeep up with the new technology ofthe oil gas storage and transportation.

In the experimental teaching content and mode, the contents of experimental teaching and basic laboratory equipment are not updated.Compared to the latest technology, the experimental method is relatively backward. At present, most ofthe teaching experiments of oil and gas storage and transportation are experiments for demonstration and validation, and the experimental methods, content and steps are usually carried out in accordance with the book, which largely limits the students' enthusiasm, initiative and creativity. Therefore, at present, the experiment teaching cannot meet the needs of the professional development of oil and gas storage and transportation.

\section{III.In view of the present situation of professional teaching practice, the following recommendations are given:}

1. Improve the production practice bases, complete practice teaching environment, update the outline of production practice, and standardize the practice content, practice and planning process. Production practice is an important link of practice teaching, and we must establish and improve the practice bases, which will not only have the main process flow of the oil production and commonly used tools and equipment, but also can provide a full range of security for the practice teaching, as well as improve the quality of the internship. Schools which do not have these conditions can unite with the cartel school, and guarantee the students' internship quality. Meanwhile, in order to give the students better guidance, the school may also appoint specialized technical people as practice guidance teachers. To help students understand the content and practice better and master the content of the status of each process in oil and gas storage and transportation field, teachers can follow the outline to give lectures and explain the engineering entity in mechanism ${ }^{[1]}$.After creating the perfect internship base, you should investigate in detail according to the process equipment, combinewith the characteristics of oil and gas storage and transportation engineering, rewrite the syllabus, and clear the requirements of practice content and practice Requirements. In practice, ensure that the students have enough time to operatethe equipment, andbe skilled.To avoid the emergence of personal danger, the premise is under the teacher's supervision. After the internship, in order to ensure the effect of thepractice, the students should be investigated.

2. Strengthen the construction of laboratory, improve experiment teaching materials, and promote the standardization of experiment teaching. Research the latest Laboratory equipment, improve the school laboratory equipment andprovide thestudents with good experimental conditions. At the same time, in order to adapt to the new development of the experiment, the teachers should write new experimental teaching materials, because of that good experimental teaching materials can improve the quality of teaching. When Compiling teaching materials, the teacher should pay attention to the progressiveness, scientificalness, practicability, and inspiring of the textbook contents. And implement the principle of combining theory and practice, which will cultivate the analysis and thinking abilities of students. The newest experimental teaching material can reflect the modern oil and gas storage and transportation experimental techniques, and the new textbook should be characterized withinspiration and creativity.It should pay attention to the training of students' practical ability and innovative consciousness, andchange the past mode of operating completely according to the textbook step by step. To make a long story short, we should change the traditional teaching mode. When making improvements in the teaching of professional courses and professional practice teaching, we also need to pay attention to the combination of classroom and practice. Only apply the class contentsto the production practice, can the students deepen the understanding of classroom knowledge. Especially in terms of oil and gas storage and transportation professional, strengthen practice teaching can train the students to work independently. The quality of Professional practice teaching is directly related to whether the students meetthe requirements of professional training objectives, and the students' adaptabilitiesafter employments. In the process of implementing the teaching plan, we cannot weaken the specialized theoretical teaching for strengthening the practice teaching; either increases the practice teaching funds too much because of the need of strengthening the practice teaching. We can only change the educational ideology, 
quality education concept and teaching concept, reform content and methods of practice teaching, pay attention to practical teaching work, and constantly explore some new forms and effective ways in the teaching work ${ }^{[5]}$.

\section{Reference}

[1]Longxueyuan, Taiyuan,Mengjiang. Thepractice and exploration of oil and gas storage andtransportation professional practice teaching [J].Petroleum education,2009,01:91-93.

[2]Lilang. Study on improving the present situation and the teaching effectof College Classroom Teaching [J].Journal of Hengyang Normal University,2010,31(6):132-134.

[3] Yangchenguang,Zhangbaomin. Where is the road of the excellent engineer education [N].Chinese Education, 2010-10-30.

[4]Lvaihua,Guowenmin.Onoil and gas storage and transportation engineering professional course of stereoscopic teaching method [J]. Chinese Power Education,2013,10:101-102.

[5]Tianye,Fanshidong,Chenyongzhi. Oil and gas storage and transportation professional practical teaching research and discussion [J]. Science educ,2008,04:33-34. 